\title{
Short-term effects of different fertilization measures on water-stable aggregates and carbon and nitrogen of tea garden soil
}

\author{
Shengjie Huang ${ }^{1}$, Junpu Chen ${ }^{1}$, Xinpeng Ma ${ }^{1}$, Wentao Guo ${ }^{1}$, Liu Yang ${ }^{1}$, Yi'an Chen ${ }^{1}$, and Chengyi Huang ${ }^{1,2, *}$ \\ ${ }^{1}$ College of Water Conservancy and Hydropower Engineering, Sichuan Agricultural University, 625014Ya'an,China; \\ ${ }^{2}$ College of Mechanical and Electrical Engineering, Sichuan Agricultural University, 625014Ya'an,China
}

\begin{abstract}
In order to study the effects of different fertilization measures on spring tea soil in Southwest Sichuan, five treatments were set up, including no fertilization (CK), full chemical nitrogen fertilizer $(\mathrm{CN}), 50 \%$ nitrogen fertilizer $+30 \%$ organic fertilizer $+20 \%$ green fertilizer + microbial fertilizer (NOGM), 50\% nitrogen fertilizer $+30 \%$ organic fertilizer $+20 \%$ green fertilizer (NOG), $50 \%$ nitrogen fertilizer $+50 \%$ organic fertilizer + microbial fertilizer (NOM). Through the determination of the distribution, organic carbon and total nitrogen content of water stable aggregates, calculated the aggregate stability and carbon and nitrogen contribution rate. The results showed that :(1) compared with CK, fertilization could improve the organic carbon and total nitrogen of soil and the organic carbon and total nitrogen of the aggregates of all sizes. Different fertilization measures had different effects on the distribution of aggregates, but compared with $\mathrm{CK}$, fertilization effectively promoted the stability of aggregates. Fertilization can obviously increased the content of organic carbon and total nitrogen in large aggregates. The contribution rate of organic carbon and total nitrogen in aggregates was mainly from macroaggregates, while that from micro-aggregates was very low. NOGM and NOM were better than other fertilization measures.
\end{abstract}

\section{Introduction}

As the basic unit of soil structure, soil aggregates can coordinate water, fertilizer, gas and heat and provide a good environment for nutrient supply and demand ${ }^{[1-2]}$. In addition, aggregates not only have a physical protective effect on organic carbon, but also play different roles in the supply and transformation of nutrients ${ }^{[3]}$, and soil organic carbon (OC) and total nitrogen (TN) are important factors affecting soil structure ${ }^{[4]}$.

Fertilization is one of the most profound agricultural measures affecting soil quality evolution and sustainable utilization ${ }^{[5]}$. It was found in the study ${ }^{[6]}$ that soil organic carbon and total nitrogen were mainly distributed in large aggregates under long-term localized fertilization treatment. $\mathrm{Li}^{\left[{ }^{7]}\right.}$ found that such as ordinary organic fertilizer with chemical fertilizer can increase than control $>0.25 \mathrm{~mm}$ aggregate content of water stability, low quantity with lower biological organic fertilizer with ordinary organic fertilizer rates increased the geometric mean diameter of mechanically stable aggregate, while biological bacterium agent and chemical fertilizer can increase soil organic matter and total nitrogen ${ }^{[8]}$

Tea tree is an important cash crop in China, with a long planting history and a wide planting area. Sichuan is an important tea industry base in China. There are three major tea producing areas in northeast Sichuan, southwest Sichuan and south Sichuan, and Mingshan
District of Ya 'an city is a typical representative area of tea producing areas in southwest Sichuan. Spring tea is the most important season of tea picking, which is related to the annual income of tea farmers. However, there are few studies on the short-term effect of fertilization on spring tea soil in southwest Sichuan tea gardens, which need to be further explored. Therefore, based on the famous mountain area, the study on the effects of different fertilization measures on spring tea soil aggregates and carbon and nitrogen can provide some scientific basis for scientific fertilization and soil quality management of tea gardens in southwest Sichuan.

\section{Materials and methods}

\subsection{Study area}

Experimental zone is located in Lianjiang township, Mingshan district, Sichuan province (east longitude $103^{\circ} 21^{\prime} 35^{\prime \prime}$, north latitude $\left.30^{\circ} 11^{\prime} 15^{\prime \prime}\right)$, is a humid subtropical monsoon climate, annual rainfall of 1500 $\mathrm{mm}$, annual average temperature of $15.4^{\circ} \mathrm{C}$, annual average frost-free period of 298 days, annual average sunshine of 1018 hours, annual average relative humidity of $82 \%$. Soil type is yellow soil, bulk density $1.18 \mathrm{~g} \cdot \mathrm{cm}^{-3}$, moisture content $20.94 \%$, pH4.3, organic carbon content $23.40 \mathrm{~g} \cdot \mathrm{kg}^{-1}$, total nitrogen $2.07 \mathrm{~g} \cdot \mathrm{kg}^{-1}$, available nitrogen 
$251.92 \mathrm{mg} \cdot \mathrm{kg}^{-1}$, available phosphorus $71.50 \mathrm{mg} \cdot \mathrm{kg}^{-1}$ and available potassium $484.08 \mathrm{mg} \cdot \mathrm{kg}^{-1}$.

\subsection{Experimental design and management}

The experiment started in September 2018, with Fuyun No. 4 tea tree and spring tea soil as the research object. Five treatments were set in the experiment, namely no fertilizer (CK), full chemical nitrogen fertilizer $(\mathrm{CN}), 50 \%$ nitrogen fertilizer $+30 \%$ organic fertilizer $+20 \%$ green fertilizer + microbial fertilizer (NOGM), $50 \%$ nitrogen fertilizer $+30 \%$ organic fertilizer $+20 \%$ green fertilizer (NOG), 50\% nitrogen fertilizer $+50 \%$ organic fertilizer + microbial fertilizer (NOM). The organic fertilizer was the rabbit manure after being piled up, and the dry matter nutrient contents after decomposition were N $31.76 \mathrm{~g} \cdot \mathrm{kg}^{-1}, \mathrm{P} 12.50 \mathrm{~g} \cdot \mathrm{kg}^{-1}, \mathrm{~K}$ $32.27 \mathrm{~g} \cdot \mathrm{kg}^{-1}$ respectively. The green fertilizer was milk vetch, and the dry matter nutrient contents were $\mathrm{N} 32.6$ $\mathrm{g} \cdot \mathrm{kg}^{-1}, \mathrm{P} 3.4 \mathrm{~g} \cdot \mathrm{kg}^{-1}, \mathrm{~K} 32.8 \mathrm{~g} \cdot \mathrm{kg}^{-1}$, which were applied together with the fertilizer after cutting. Three replicates were set for each treatment, a total of 15 plots, with each plot covering an area of $20 \mathrm{~m}^{2}(5 \mathrm{~m} \times 4 \mathrm{~m})$, randomly distributed, and isolation bands were set between the plots. The total nitrogen application amount of tea garden was $400 \mathrm{~kg} \cdot \mathrm{hm}^{-2}$, every treatment in equal nitrogen level, other management according to local customs.

\subsection{Soil sampling}

Soil samples were collected in March 2020. Soil samples with a depth of $0-20 \mathrm{~cm}$ in each experimental plot were collected according to the S-shaped sampling method, and then placed in sealed bags and brought back to the laboratory. Break the soil sample into blocks of about $10 \mathrm{~mm}$ in the room, remove the visible animal and plant residues and rocks, and air dry in a cool and ventilated place.

The air-dried soil was passed through a $10 \mathrm{~mm}$ stainless steel sieve and $50 \mathrm{~g}$ soil samples were weighed. The aggregate of $>2 \mathrm{~mm}, 2-0.25 \mathrm{~mm}, 0.25-0.053 \mathrm{~mm}$ and $<0.053 \mathrm{~mm}$ in the tested soil was determined by improved Elliott ${ }^{[9]}$ wet sieve method. The aggregate of $>0.25 \mathrm{~mm}$ was called macro aggregate and the aggregate of $<0.25 \mathrm{~mm}$ was called micro aggregate. The wet sifted sample was washed into a beaker and dried in an oven at $60^{\circ} \mathrm{C}$. Then the soil sample was ground and passed through a $0.25 \mathrm{~mm}$ mesh sieve for testing.

\subsection{Soil analysis}

The organic carbon was determined by potassium dichromatate external heating method, and the total nitrogen was determined by Kjeldahl nitrogen method [10].

The content of the analysis included the mass percentage of aggregates of different sizes, the stability of aggregates and the contribution rate of organic carbon and total nitrogen in aggregates. The specific calculation methods were as follows ${ }^{[11,6]}$ :

Percentage of aggregate mass: $M_{i} / M_{T} \times 100 \%$

Type: $M_{i}$ denotes the aggregate mass of each granule, $M_{T}$ denotes the aggregate total weight.

Aggregate stability was expressed by macro aggregate content (R0.25), mean weight diameter (MWD) and geometric mean diameter (GMD).

$$
\begin{aligned}
& R_{0.25}=M_{r>0.25} / M_{T} \\
& M W D=\sum\left(M_{i} / M_{T}\right) X_{i} \\
& G M D=\exp \left\{\sum\left(M_{i} / M_{T}\right) \ln X_{i}\right\}
\end{aligned}
$$

Where $M_{r>0.25}$ denotes the aggregate weight greater than $0.25 \mathrm{~mm}, M_{T}$ denotes the aggregate total weight, $M_{i}$ denotes the mass of the aggregates of each grain size, and $X_{i}$ denotes the average diameter of the aggregates.

Contribution rate of organic carbon (total nitrogen) in the aggregates $=$ content of organic carbon (total nitrogen) in the aggregates/content of organic carbon (total nitrogen) in the each layer $\times$ mass ratio of the aggregates $\times 100 \%$

\subsection{Statistical analysis}

Excel was used for preliminary data processing and chart making, SPSS21.0 for one-way ANOVA, LSD method was used for difference analysis, and different lowercase letters were used to indicate the significant difference between the treatments $(\mathrm{P}<0.05)$.

\section{Results}

\subsection{Effects of different fertilization measures on soil organic carbon and total nitrogen}

The regularity of soil organic carbon content $\mathrm{NOM}>\mathrm{NOGM}>\mathrm{NOG}>\mathrm{CN}>\mathrm{CK}, \mathrm{CK}$ had significant difference with the other three treatments except $\mathrm{CN}$ (Fig.1.a). While the regularity of soil total nitrogen $\mathrm{NOM}>\mathrm{NOGM}>\mathrm{CN}>\mathrm{NOG}>\mathrm{CK}, \mathrm{NOM}$ and the other four treatments had significant differences(Fig.1.b), $\mathrm{CN}, \mathrm{NOGM}$ and NOG had no significant differences, CK and the other four treatments also had significant differences. 


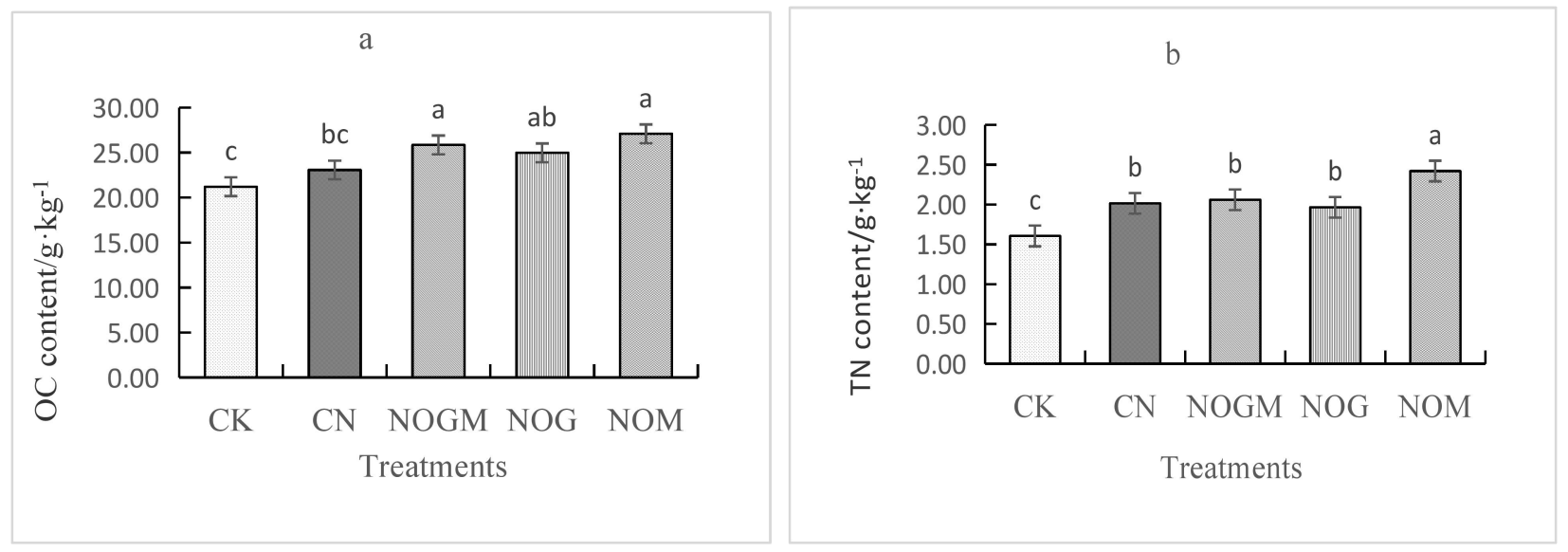

Fig. 1.Soil organic carbon and total nitrogen under different fertilization measures

Note: Different lowercase letters indicate significant difference between different treatments of the same aggregate size $(\mathrm{P}<0.05)$. The same below.

\subsection{Effects of different fertilization measures on the distribution of water-stable aggregates}

Aggregate distribution under all fertilization measures showed the same rule(Table 1.), > $2 \mathrm{~mm}$ aggregate mass percentage was the highest, ranging from $30.47 \%$ to $62.87 \%, 2-0.25 \mathrm{~mm}$ aggregate mass percentage was second, ranging from $27.02 \%$ to $49.62 \%$, $0.25-0.053 \mathrm{~mm}$ aggregate mass percentage was third, ranging from $1.95 \%$ to $12.13 \%$, and $<0.053 \mathrm{~mm}$ aggregate mass percentage was lowest, ranging from $1.54 \%$ to $8.07 \%$.

Under different fertilization measures, $>2 \mathrm{~mm}$ aggregate mass percentage under $\mathrm{CN}$ was highest, reaching $62.87 \%$, which was significantly different from NOGM, NOG and CK. NOM was slightly lower than
$\mathrm{CN}$, which was significantly different from NOGM, NOG and CK. CK was the smallest, only $30.47 \%$, which was significantly different from the other four treatments. The aggregate mass percentage of $2-0.25 \mathrm{~mm}$ was the highest in NOG, $49.62 \%$; followed by $\mathrm{CK}$, no significant difference between NOG and $\mathrm{CK}$, however significant difference between $\mathrm{CK}$ and CN, NOGM, NOM, CN was the lowest, $27.02 \%$, which was significantly different from the other four treatments. CK was the highest mass percentage of $0.25-0.053 \mathrm{~mm}$ aggregate, followed by $\mathrm{CN}$, NOG, NOGM and NOM. Among them, except NOGM and NOG had no significant difference, there were significant differences with each other. The rule of $<0.053 \mathrm{~mm}$ mass percentage was similar to that of $0.25-0.053 \mathrm{~mm}$, but there was no significant difference among NOGM, NOG and NOM.

Table 1. Distribution of water-stable aggregates under different fertilization measures (\%)

\begin{tabular}{lcccc}
\hline & \multicolumn{4}{c}{ Aggregate Size $/ \mathrm{mm}$} \\
\cline { 2 - 5 } Treatments & $>2$ & $2-0.25$ & $0.25-0.053$ & $<0.053$ \\
\hline CK & $30.47 \pm 0.98 \mathrm{~d}$ & $49.33 \pm 1.44 \mathrm{a}$ & $12.13 \pm 0.18 \mathrm{a}$ & $8.07 \pm 0.53 \mathrm{a}$ \\
CN & $62.87 \pm 0.93 \mathrm{a}$ & $27.02 \pm 0.25 \mathrm{~d}$ & $5.26 \pm 0.28 \mathrm{~b}$ & $4.85 \pm 0.53 \mathrm{~b}$ \\
NOGM & $50.01 \pm 0.96 \mathrm{~b}$ & $44.44 \pm 1.10 \mathrm{~b}$ & $3.49 \pm 0.03 \mathrm{c}$ & $2.06 \pm 0.12 \mathrm{c}$ \\
NOG & $44.12 \pm 0.58 \mathrm{c}$ & $49.62 \pm 0.57 \mathrm{a}$ & $4.09 \pm 0.36 \mathrm{c}$ & $2.17 \pm 0.07 \mathrm{c}$ \\
NOM & $59.95 \pm 0.27 \mathrm{a}$ & $36.56 \pm 0.46 \mathrm{c}$ & $1.95 \pm 0.10 \mathrm{~d}$ & $1.54 \pm 0.15 \mathrm{c}$ \\
\hline
\end{tabular}

\subsection{Effects of different fertilization measures on the stability of water-stable aggregates}

The macro aggregate contents of CK, CN, NOGM, NOG and NOM were $79.80 \%, 89.89 \%, 94.45 \%, 93.74$ and $96.51 \%$, respectively(Table 2.). NOM and the other four treatments have significant differences, NOGM and NOG had no significant differences, and they had significant differences with $\mathrm{CK}$ and $\mathrm{CN}$, while $\mathrm{CN}$ and
CK had significant differences. Compared with CK, the MWD values under CN, NOGM, NOG and NOM were significantly improved by $31.93 \%, 26.89 \%, 21.85 \%$ and $35.29 \%$, respectively. Moreover, there were significant differences between CN,NOGM,NOG and NOM.The GMD values under CN, NOGM, NOG and NOM were significantly increased by $52.44 \%, 59.76 \%, 52.44 \%$, $78.05 \%$, respectively, compared with $\mathrm{CK}$, and there was no significant difference between $\mathrm{CN}$ and NOG, among the others had significant differences. 
Table 2. Water stability aggregates R0.25, MWD and GMD under different fertilization measures

\begin{tabular}{cccc}
\hline & \multicolumn{3}{c}{ Aggregate Stability } \\
\cline { 2 - 4 } Treatments & $\mathrm{R}_{0.25}$ & MWD & GMD \\
\hline CK & $79.80 \pm 0.76 \mathrm{~d}$ & $1.19 \pm 0.01 \mathrm{e}$ & $0.82 \pm 0.01 \mathrm{~d}$ \\
CN & $89.89 \pm 1.61 \mathrm{c}$ & $1.57 \pm 0.02 \mathrm{~b}$ & $1.25 \pm 0.07 \mathrm{c}$ \\
NOGM & $94.45 \pm 0.28 \mathrm{~b}$ & $1.51 \pm 0.01 \mathrm{c}$ & $1.31 \pm 0.01 \mathrm{~b}$ \\
NOG & $93.74 \pm 0.62 \mathrm{~b}$ & $1.45 \pm 0.01 \mathrm{~d}$ & $1.25 \pm 0.02 \mathrm{c}$ \\
NOM & $96.51 \pm 0.49 \mathrm{a}$ & $1.61 \pm 0.00 \mathrm{a}$ & $1.46 \pm 0.02 \mathrm{a}$ \\
\hline
\end{tabular}

\subsection{Effects of different fertilization measures on organic carbon and total nitrogen in aggregates}

$>2 \mathrm{~mm}$ aggregate, $2-0.25 \mathrm{~mm}$ aggregate and $<0.053 \mathrm{~mm}$ aggregate had similar organic carbon content(Fig.2.a), with $\mathrm{NOM}>\mathrm{NOGM}>\mathrm{NOG}>\mathrm{CN}>\mathrm{CK}$, however organic carbon content in $0.25-0.053 \mathrm{~mm}$ aggregate $\mathrm{NOM}>\mathrm{NOGM}>\mathrm{CN}>\mathrm{NOG}>\mathrm{CK}$. In addition, with the exception of the organic carbon content of $0.25-0.053 \mathrm{~mm}$ aggregate, NOM and NOGM showed no significant difference, and they were significantly different from the other three treatments. There was no significant difference between $\mathrm{CK}$ and $\mathrm{CN}$.

The total nitrogen content in $2-0.25 \mathrm{~mm}$ aggregate, $0.25-0.053 \mathrm{~mm}$ aggregate and $<0.053 \mathrm{~mm}$ aggregate had similar rules: $\mathrm{NOM}>\mathrm{NOGM}>\mathrm{CN}>\mathrm{NOG}>\mathrm{CK}$, and $>2 \mathrm{~mm}$ aggregate had $\mathrm{NOM}>\mathrm{NOGM}>\mathrm{NOG}>\mathrm{CN}>\mathrm{CK}$ (Fig.2.b). Moreover, the total nitrogen content of NOM in all aggregate sizes were not significantly different from that in NOGM and significantly different from that in CK.

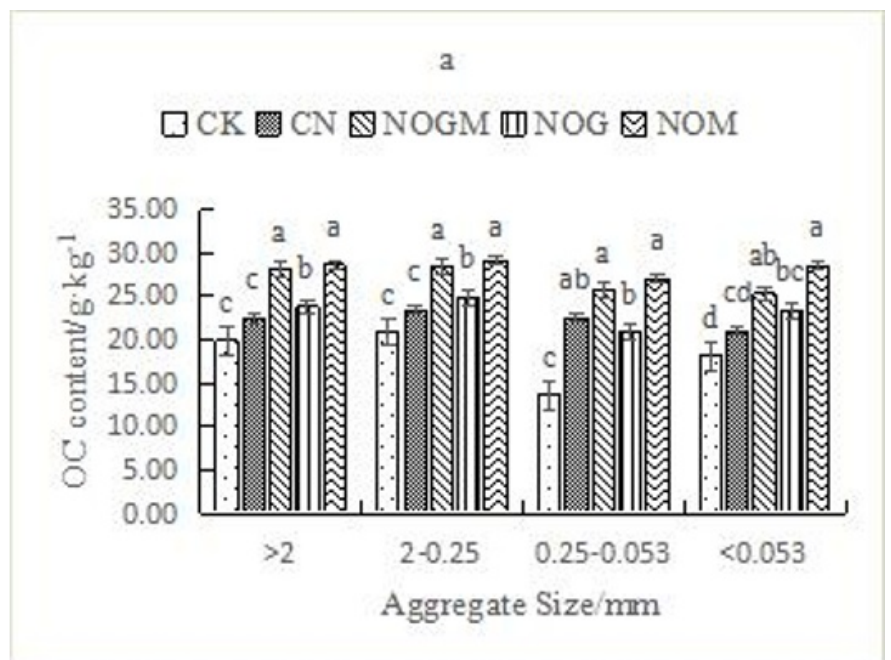

$\mathrm{b}$

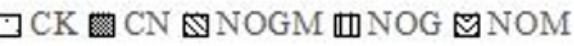

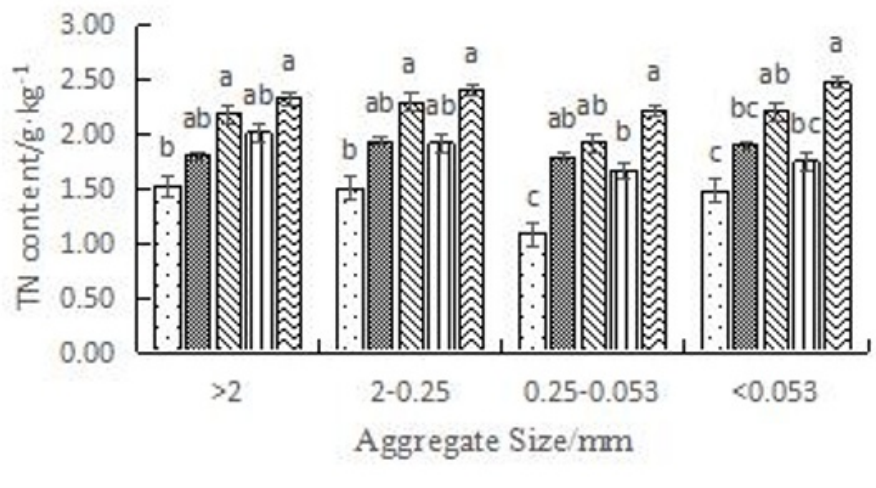

Fig. 2. Organic carbon and total nitrogen of aggregates under different fertilization measures

\subsection{Effects of different fertilization measures on contribution rates of organic carbon and total nitrogen in aggregates}

The contribution rate of organic carbon in large aggregates was significantly higher than that in micro aggregates(Table 3.). The contribution rates of $>2 \mathrm{~mm}$ aggregate $\mathrm{CK}, \mathrm{CN}, \mathrm{NOGM}, \mathrm{NOG}$ and NOM were $28.59 \%, \quad 61.14 \%, \quad 54.81 \%, \quad 41.82 \%$ and $63.77 \%$, respectively. There was no significant difference between CN, NOGM and NOM, which was significantly different from NOG and $\mathrm{CK}$, and NOG was significantly higher than that of $\mathrm{CK}$. The contribution rates of organic carbon in $\mathrm{CK}, \mathrm{CN}$, NOGM, NOG and NOM in $2-0.25 \mathrm{~mm}$ aggregate was $48.54 \%, 27.40 \%, 51.46 \%$, $51.18 \%$ and $39.83 \%$, respectively. There was no significant difference between CK, NOGM and NOG, and it had significant difference with $\mathrm{CN}$ and NOM, and NOM was significantly higher than $\mathrm{CN}$. The regularity of contribution rate of organic carbon in $0.25-0.053 \mathrm{~mm}$ aggregate and $<0.053 \mathrm{~mm}$ aggregate was similar. $\mathrm{CK}>\mathrm{CN}>\mathrm{NOGM}>\mathrm{NOG}>\mathrm{NOM}, \mathrm{CK}$ and $\mathrm{CN}$ were significantly different from the other three treatments, and $\mathrm{CK}$ was significantly higher than $\mathrm{CN}$.

The contribution rate of total nitrogen in macro aggregates were also significantly higher than that in micro aggregates. The contribution rate of total nitrogen in $>2 \mathrm{~mm}$ aggregates under $\mathrm{CN}$, NOGM, NOG and NOM was significantly higher than that under $\mathrm{CK}$; $\mathrm{CN}$, NOGM, NOG and NOM in $2-0.25 \mathrm{~mm}$ aggregate was $46.46 \%, \quad 26.09 \%, \quad 54.09 \%, \quad 56.74 \%$ and $36.82 \%$, respectively. There was no significant difference between NOGM and NOG, which was significantly different from the other three treatments. The total nitrogen contribution rate of the aggregate $<0.053 \mathrm{~mm}$ was similar to that of $\mathrm{CK}>\mathrm{CN}>\mathrm{NOG}>\mathrm{NOGM}$ and $\mathrm{NOG}>\mathrm{NOM}$, the total nitrogen contribution rate of the aggregate of $0.25-0.053 \mathrm{~mm}$ had no significant difference with that of $\mathrm{CK}$ and NOM, while the total nitrogen contribution rate of the aggregate of $<0.053 \mathrm{~mm}$ had no 
significant difference with that in CK and NOM, and had

significant difference with that in CK and NOM.

Table 3. Contribution rate of organic carbon and total nitrogen in aggregates under different fertilization measures (\%)

\begin{tabular}{cccccc}
\hline Contribution & & \multicolumn{4}{c}{ Aggregate Size $/ \mathrm{mm}$} \\
\cline { 3 - 6 } Rate & Treatments & $>2$ & $2-0.25$ & $0.25-0.053$ & $<0.053$ \\
\hline & $\mathrm{CK}$ & $28.59 \pm 2.22 \mathrm{c}$ & $48.54 \pm 1.19 \mathrm{a}$ & $7.76 \pm 0.43 \mathrm{a}$ & $6.93 \pm 1.65 \mathrm{a}$ \\
$\mathrm{NCC}$ & $\mathrm{CN}$ & $61.14 \pm 1.53 \mathrm{a}$ & $27.40 \pm 1.75 \mathrm{c}$ & $5.14 \pm 0.58 \mathrm{~b}$ & $4.41 \pm 0.88 \mathrm{~b}$ \\
& NOGM & $54.81 \pm 4.47 \mathrm{a}$ & $51.46 \pm 5.12 \mathrm{a}$ & $3.77 \pm 0.39 \mathrm{c}$ & $2.06 \pm 0.47 \mathrm{c}$ \\
& NOG & $41.82 \pm 3.53 \mathrm{~b}$ & $51.18 \pm 0.09 \mathrm{a}$ & $3.28 \pm 0.76 \mathrm{c}$ & $2.00 \pm 0.05 \mathrm{c}$ \\
& NOM & $63.77 \pm 4.83 \mathrm{a}$ & $39.83 \pm 0.13 \mathrm{~b}$ & $1.84 \pm 0.12 \mathrm{~d}$ & $1.51 \pm 0.32 \mathrm{c}$ \\
& $\mathrm{CK}$ & $28.99 \pm 2.67 \mathrm{~b}$ & $46.46 \pm 2.56 \mathrm{~b}$ & $8.21 \pm 1.01 \mathrm{a}$ & $7.48 \pm 1.06 \mathrm{a}$ \\
& $\mathrm{CN}$ & $56.42 \pm 0.82 \mathrm{a}$ & $26.09 \pm 1.46 \mathrm{~d}$ & $4.69 \pm 0.75 \mathrm{~b}$ & $4.58 \pm 0.99 \mathrm{~b}$ \\
$\mathrm{TN}$ & NOGM & $54.36 \pm 3.06 \mathrm{a}$ & $54.09 \pm 2.86 \mathrm{ab}$ & $3.47 \pm 0.16 \mathrm{~b}$ & $2.14 \pm 0.17 \mathrm{c}$ \\
& NOG & $48.74 \pm 10.68 \mathrm{a}$ & $56.74 \pm 5.66 \mathrm{a}$ & $3.71 \pm 0.73 \mathrm{~b}$ & $2.29 \pm 0.18 \mathrm{c}$ \\
& NOM & $58.46 \pm 2.03 \mathrm{a}$ & $36.82 \pm 0.51 \mathrm{c}$ & $1.70 \pm 0.08 \mathrm{c}$ & $1.52 \pm 0.37 \mathrm{c}$ \\
\hline
\end{tabular}

\section{Discussion}

\subsection{Effects of different fertilization measures on the distribution and stability of soil aggregates}

Soil aggregates are an important indicator for evaluating soil health, and organic matter is the cementing agent for soil aggregate weight, and studies have shown that long-term application of organic fertilizers can increase soil organic matter, promote the formation of large aggregates, and increase the stability of soil aggregates ${ }^{[12-14]}$. The results showed that compared with $\mathrm{CK}$ and $\mathrm{CN}$, NOGM, NOG and NOM all significantly increased the content of macro aggregates, which was consistent with the research results of Rong's study ${ }^{[15]}$. However, $\mathrm{CN}$ significantly increased the mass percentage of $>2 \mathrm{~mm}$ aggregate. It may be that the application of chemical fertilizers promoted the growth and development of tea roots, and promoted the formation of $>2 \mathrm{~mm}$ aggregate, while the application of organic fertilizers was relatively short and the effect was not significant. Compared with CK, CN, NOGM, NOG and NOMCN increased the aggregate MWD and GMD values, but $\mathrm{CN}$ had high MWD and GMD values, which may be related to the higher mass percentage of $>2 \mathrm{~mm}$ aggregate.

\subsection{Effects of different fertilization measures on organic carbon, total nitrogen and contribution rates of soil aggregates}

The return of organic materials to the fields is an important source of soil organic matter, which will inevitably lead to an increase in the total organic carbon content of the soil after entering the soil ${ }^{[16]}$, which is consistent with the results of this study. In addition, fertilization also significantly increased the total nitrogen content of the soil. Fertilizer can obviously increased the content of organic carbon and total nitrogen of macro aggregates, this is the same as previous research results ${ }^{[6]}$, but NOGM, NOG and NOM promotion effect of organic carbon was better than $\mathrm{CN}$, while $\mathrm{CN}$ promotion effect of total nitrogen was superior to NOG,on one hand, may be chemical fertilizer has high nitrogen, on the other hand, water content of fresh green manure is higher, causing the low decomposition.

The contribution rates of organic carbon and total nitrogen in all aggregate sizes were mainly from the macro aggregates, while the contribution rates of micro aggregates were very small. Moreover, the contribution rate of $>2 \mathrm{~mm}$ aggregate under CN, NOGM and NOM was higher than that of $2-0.25 \mathrm{~mm}$ aggregate, while CK and NOG were on the contrary, which was similar to the distribution regularity of aggregates.

\section{Conclusion}

(1) Compared with CK, fertilization can improve soil organic carbon and total nitrogen as well as the organic carbon and total nitrogen of all aggregate sizes, and NOGM and NOM had the most significant effects.

(2) Different fertilization measures had different effects on aggregate distribution, but compared with CK, fertilization effectively promoted the stability of aggregates. Among different fertilization measures, NOGM and NOM had the best effects.

(3) Fertilization can significantly increased the content of organic carbon and total nitrogen in macro aggregates, and NOGM and NOM had better effects. The contribution rate of organic carbon and total nitrogen in aggregates was mainly from macro aggregates, the contribution rate from micro aggregates was very low.

(4) Although some results have been achieved through the preliminary tests, the test time is relatively short, and it is still necessary for latecomers to continue this work in order to obtain longer and more abundant data. 


\section{Acknowledgement}

This work was financially supported by the Research on Key Technology of Soil Improvement in Tea Garden in Mingshan District (grant number 2019yyjskf11) .We are grateful to Mr. Li Wanlin and Mr. Chen Yong from Xiangshui Seedling Cooperative for providing place and guidance.

\section{References}

1. Z.L.Liu, W.T.Yu, Chi. J. Eco. Agr 19,2:447-455 (2011). (in Chinese)

2. M.M.Mikha, C.W.Rice, Soil Sci.Soc. Am. J 68,3:809-816 (2004).

3. E.F.Chen, L.Z.Guan, J.K.Wang, et al. Chi. J. Soil Sci 01:49-53 (2001). (in Chinese)

4. P.Zhao, D.M.Shi, P.Zhao, et al. J. Agr. Eng 22:137-144 (2013). (in Chinese)
5. E.K.Liu, B.Q.Zhao, X.R.Mei, et al. Eco. Sin 30,4 (2010). (in Chinese)

6. X.F.Chen, Z.P.Li, M.Liu, et al. Chi. J. Agr. Sci 46,005:950-960 (2013). (in Chinese)

7. R.Li, R.Tao, D.Wang, et al. J. Appl. Eco 10 (2017). (in Chinese)

8. L.Li, T.L.Li, H.S.Meng, et al. J. Appl. Env. Bio 6:1156-1160, 5 pages (2016). (in Chinese)

9. E.T.Elliott, Soil Sci. Soc. Am. J 50,3:627-633 (1986).

10. S.D.Bao, Chemical analysis of soil agriculture [M]. 3rd Ed Beijing: China Agricultural Press (1999). (in Chinese)

11. Y.Cheng, H.Ren, P.Liu, et al. J. Appl. Eco 11:3521-3528, 8 pages (2016). (in Chinese)

12. J.Zhao, S.Chen, R.Hu, et al. Soil Till. Res 167: 73-79 (2017).

13. W.Wang, W.C.Chen , H.R.Wang, et al. Agr. Sci. China, 10,12: 1932-1940 (2011). (in Chinese)

14. S.Abiven, S.Menasseri, C.Chenu. Soil Biol. Biochem 41,1:1-12 (2009)

15. Q.L.Rong, R.N., S.W.Huag, et al. J. Plant Nutr. Fertilizer, 25,7 (2019). (in Chinese)

16. H.X.Li, Y.H.Yuan, Y.R.Huang, et al. J. Soil Sci 3 (2006). 